Review

\title{
Ecological Impact of Artificial Light at Night: Effective Strategies and Measures to Deal with Protected Species and Habitats
}

\author{
Annika K. Jägerbrand ${ }^{1,2, *}$ and Constantinos A. Bouroussis ${ }^{3}$ (D) \\ 1 Calluna AB, Hästholmsvägen 28, SE-131 30 Nacka, Sweden \\ 2 Department of Environmental and Biosciences, Rydberg Laboratory of Applied Science (RLAS), \\ School of Business, Engineering and Science, Halmstad University, P.O. Box 823, SE-301 18 Halmstad, Sweden \\ 3 Lighting Laboratory, School of Electrical and Computer Engineering, National Technical University of Athens, \\ 15780 Zografou, Greece; costisb@mail.ntua.gr \\ * Correspondence: annika.jagerbrand@hh.se
}

Citation: Jägerbrand, A.K.;

Bouroussis, C.A. Ecological Impact of Artificial Light at Night: Effective Strategies and Measures to Deal with Protected Species and Habitats. Sustainability 2021, 13, 5991. https:// doi.org/10.3390/su13115991

Academic Editor: Carlos Sanz-Lazaro

Received: 9 April 2021

Accepted: 18 May 2021

Published: 26 May 2021

Publisher's Note: MDPI stays neutral with regard to jurisdictional claims in published maps and institutional affiliations.

Copyright: (c) 2021 by the authors. Licensee MDPI, Basel, Switzerland. This article is an open access article distributed under the terms and conditions of the Creative Commons Attribution (CC BY) license (https:// creativecommons.org/licenses/by/ $4.0 /)$.

\begin{abstract}
When conserving or protecting rare or endangered species, current general guidelines for reducing light pollution might not suffice to ensure long-term threatened species' survival. Many protected areas are exposed to artificial light at levels with the potential to induce ecological impacts with unknown implications for the ecosystems they are designated to protect. Consequently, it is recommended that precautionary methods for the avoidance and mitigation of light pollution in protected areas be integrated into their management plans. This paper's aims are to present an overview of best practices in precautionary methods to avoid and mitigate light pollution in protected areas and to identify and discuss what ecosystems should be considered light-sensitive and how to prioritise species and habitats that need protection from artificial light, including examples of legislation covering ecological light pollution in the European Union and in Sweden. The important aspects to include when considering light pollution at a landscape level are listed, and a proposal for prioritisation among species and habitats is suggested. Sensitive and conservation areas and important habitats for particularly vulnerable species could be prioritised for measures to minimise artificial lighting's negative effects on biodiversity. This may be done by classifying protected natural environments into different zones and applying more constrained principles to limit lighting. The light pollution sensitivity of various environments and ecosystems suggests that different mitigation strategies and adaptations should be used depending on landscape characteristics, species sensitivity and other factors that may determine whether artificial light may be detrimental. Issues of the currently used measurement methods for artificial light at night are reviewed. We also propose and discuss the principles and benefits of using standardized measurement methods and appropriate instrumentation for field measurements of artificial light concerning the environmental impact of light pollution.
\end{abstract}

Keywords: biodiversity; red list; precautionary principle; light pollution; mitigation; light measurements

\section{Introduction}

Light has different biological and ecological impacts depending on the spectral power distribution (SPD) of the emitted light, the strength of the light source, the distance to and direction of the light, if the light is polarised and if the light is modulated in time (flickering effect), etc. Conversely, for nocturnal species, darkness or very low light levels are important, and exposure to artificial light can have unwanted ecological consequences [1]. Light is fundamental for the survival of most animal and plant species, being crucial for vision, orientation and physiological processes, and for adaptation to diurnal and seasonal changes [2]. For plants and organisms that possess chlorophyll, light is the very foundation of life since they depend on photosynthesis. 
Ecological light pollution may be defined as any artificial light that alters the natural patterns of light and dark in ecosystems [3]. Artificial light is increasing over the Earth's surface at a rate of approximately $6 \%$ annually, with variations of $0-20 \%$ per year depending on the geographical area [4-6]. Artificial light from anthropogenic sources might, in biological organisms, interfere with physiological functions, health and circadian rhythms, leading to impaired foraging, orientation and communication, increased predation risk and consequently poorer reproduction and population survival [2] (Table 1).

Table 1. Artificial light's ecological and functional impacts.

\begin{tabular}{ll}
\hline Ecological Impacts & Functional Impacts \\
\hline Mortality & Species attracted to light may be killed \\
\hline Migration & $\begin{array}{l}\text { Artificial light disturbs natural movement patterns, } \\
\text { migration and orientation }\end{array}$ \\
\hline Population size & Reduced or increased foraging because of presence of light \\
\hline Indirect competition & Light can benefit certain species at the expense of others \\
\hline Communication & Light can disturb species communication \\
\hline Health and circadian rhythm & $\begin{array}{l}\text { Light can influence various physiological processes that } \\
\text { can impact health and circadian rhythm }\end{array}$ \\
\hline
\end{tabular}

The ecological impact of artificial light affects many taxa, with serious ecological implications [7,8]. Ecological consequences include risks of adverse effects on biodiversity at all organisational levels: populations, species interactions, species composition and ecosystems [9-11]. The responses to and impact of artificial light can differ between species and also depend on the time of year [12,13]. Light pollution from artificial light has been shown to jeopardise important ecosystem services; for example, artificial light at night (ALAN) may disrupt nocturnal pollination [14] and pollination networks, leading to negative consequences for plant reproductive success [15].

Current general guidelines for light pollution reduction locally, e.g., [16-18] or regionally $[18,19]$ might not be adequate to ensure species survival [13]. Protected areas aim to achieve long-term conservation of nature with associated ecosystem services and cultural values [20] and maintain a buffer against anthropogenic pressures such as light pollution. Pressures within the protected area may be handled by management plans, while pressures outside the protected area will require legislation or regulations [21]. Yet, protected areas are already exposed to artificial light at levels with the potential to induce ecological impacts with unknown implications for the ecosystems they are designated to protect [21-23].

Implications for biodiversity in protected areas have been identified in Australia and include potential impacts on reproductive success, loss of ecosystem function, reduction in effectively conserved habitats and additive effects from subsequent development [22]. Major challenges involve long-term nature conservation in protected areas threatened by light pollution and the lack of legislation at global, national, regional or local levels to protect against ecologically harmful light pollution levels. In addition, empirical data on the effects of artificial light on species and habitats are lacking, see, e.g., [22]. The quantification between ecological impact and light levels, spectral content and directionality is a research area where much remains to be discovered. However, current knowledge on the ecological impact of artificial light demonstrates a high risk of adverse impact, especially for lightsensitive or nocturnal species and sensitive habitats.

Consequently, it is recommended that precautionary methods for the avoidance and mitigation of light pollution in protected areas be implemented $[13,22]$. Precautionary methods and principles should be integrated in the management plans of protected areas, focusing on local impact, and in national legislation or guidelines to control light pollution on a large scale, such as skyglow. 
The aim of this review paper is to present an overview of the best practices of various precautionary methods for avoidance and mitigation of light pollution in protected areas and identify what ecosystems should be considered light-sensitive and how to prioritise species and areas that need protection, giving examples of legislation that covers ecological light pollution. The paper also discusses field lighting measurement methods, their contribution to the justification of the environmental impact of ALAN and known issues around light pollution metrology.

The paper starts by describing legislation for protected species and habitats in the European Union (EU) and in Sweden to give an overview of how light pollution may be considered and handled (Section 2). Section 3 presents established guidelines for outdoor lighting in protected or sensitive environments, and Section 4 describes environmental zone systems that can be used in planning outdoor lighting. Sections 5 and 6 discuss the prioritisation of protected species and groups and the sensitivity of environments and ecosystems to light pollution. Ecological concepts for working with light pollution at the landscape level are described in Section 7. Section 8 discusses the field measurement aspects, and Section 9 concludes the paper.

\section{Legislation}

\subsection{European Legislation}

The European legislation regarding the environmental implications of decisions is handled by the Environmental Impact Assessment Directive for individual projects [24] and the Strategic Environmental Assessment Directive for public plans or programmes [25]. The directives aim to provide a high level of environmental protection and ensure that plans or projects with an environmental impact are subject to environmental assessment [26].

The EU Birds and Habitats Directives [27,28] aim to ensure the conservation of threatened and endangered species and habitats across EU member states. Species and habitats listed in the Birds and Habitats Directives must be maintained or restored to a favourable status. The Birds Directive states (Article 5) "... Member States shall take the requisite measures to establish a general system of protection for all species of birds referred to in Article 1 , prohibiting in particular: (a) deliberate killing or capture by any method; $(b)$ deliberate destruction of, or damage to, their nests and eggs or removal of their nests; (c) taking their eggs in the wild and keeping these eggs even if empty; (d) deliberate disturbance of these birds particularly during the period of breeding and rearing, in so far as disturbance would be significant having regard to the objectives of this Directive."

The Habitat Directive (Article 12) has similar stipulations: "Member States shall take the requisite measures to establish a system of strict protection for the animal species listed in Annex IV (a) in their natural range, prohibiting: (a) all forms of deliberate capture or killing of specimens of these species in the wild; (b) deliberate disturbance of these species, particularly during the period of breeding, rearing, hibernation and migration; $(c)$ deliberate destruction or taking of eggs from the wild; (d) deterioration or destruction of breeding sites or resting places."

Consequently, deliberate disturbances of species listed in the Birds and Habitats Directive are forbidden, and particular care should be taken to avoid disturbance during significant periods of the life cycle, such as breeding or migration. Whether the provisions of these directives also include lighting is further discussed below.

EU countries must ensure the physical conservation of core breeding and resting sites, especially for rare and threatened species, in the Natura 2000 network through implementing the Birds [28] and the Habitats directives [27]. The Natura 2000 network aims to safeguard the long-term survival of Europe's most valuable and threatened species and habitats. The main objectives are to [29]:

- " avoid activities that could seriously disturb the species or damage the habitats for which the site is designated";

- "take positive measures, if necessary, to maintain and restore these habitats and species to improve conservation". 
The European Red List provides information on identifying threatened species for prioritisation in nature conservation. Species status is reviewed in accordance with the International Union for Conservation of Nature (IUCN) guidelines, and the European Red List is compiled by the IUCN's species programme and species survival commission and European Regional Office [30].

As an example of the application of European legislation to light pollution, in 2016, the European Court of Justice ruled that Greece had failed to fulfil its obligations under the Habitats Directive "by failing to take the measures necessary so as to ensure that the light pollution affecting the breeding beaches of the Caretta caretta sea turtle in the Kyparissia area is adequately curtailed...".

Municipal street lighting, beach lighting and light from restaurants, hotels and shops in the surrounding area and the development of houses and streets caused deterioration and destruction of the breeding sites of the species (Case C-504/14, Court of Justice judgement, 10 November 2016). Sea turtles are vulnerable to disorientation from artificial light close to their nesting areas [31], and light on nesting beaches can be detrimental, since hatchlings cannot then find their way to the sea after hatching [32].

The ability of European environmental laws to protect species and habitats from ALAN has been questioned, since difficulty in providing evidence on the negative impacts of ALAN on population levels or survival or evidence of lighting malpractice raise concerns that it is difficult to provide sufficient evidence for species disturbance or habitat damage [33].

\subsection{Swedish Legislation}

Swedish legislation includes several statutes for the protection of the environment and protected areas, of which several are similar to the European legislation. The legislation for roads and railways states that information about possible environmental effects (where artificial light is a possible effect) and as listed in the Swedish Environmental Code must be included and considered when planning new roads or railways, including the effects of operation and maintenance [34-36]. The Planning and Building Act [37] stipulates that consideration be given to environmental aspects and to promoting green areas and good environmental conditions.

The Swedish Environmental Code is of special interest with regard to light pollution and its ecological impact: "Persons who pursue an activity, take a measure, or intend to do so, shall implement protective measures, comply with restrictions and take any other precautions to prevent, hinder or combat damage or detriment to human health or the environment as a result of the activity or measure. For the same reason, the best possible technology shall be used in connection with professional activities. Such precautions shall be taken as soon as there is cause to assume that an activity or measure may cause damage or detriment to human health or the environment."

Consequently, if outdoor lighting is believed to cause damage or detriment to the environment, precautionary measures must be implemented.

In Sweden, the Species Protection Ordinance [38] includes legislation from both the EU Birds Directive and the Habitats Directive. This ordinance states (4 §) (author's translation): "In the case of wild birds and in the case of wild animals (marked with N/n in Appendix 1) ... it is prohibited to ... 1. Deliberately capture or kill animals; 2 . Deliberately disturb animals, especially during breeding, rearing, hibernation and migration; ... 4. Deteriorate or destroy breeding sites or resting places."

The prohibition includes all wild birds, bats, frogs and toads and the northern crested newt (Triturus cristatus) and applies to all life stages of the animals. In Sweden, the protection of wild birds is stronger than the Birds Directive. The Swedish Environmental Protection Agency (SEPA) recommends prioritising wild birds that are included in the Red List and species with a negative trend [39]. The Swedish red list follows the IUCN system and is a compilation of the status of species and their risk of extinction. Of the evaluated species in 2015, 4273 species were categorised as red-listed and 2029 as threatened [40]. The red list is a tool for prioritising nature conservation but lacks legal status. 
There is no clear definition of disturbance, but the SEPA clarifies that noise or light can be disturbances and that impact can be indirect [39]. The clarification may be used as a good example of best praxis for other countries to more efficiently deal with the adverse and unwanted ecological impact of ALAN on protected species and/or habitats. Indirect impacts include disturbances that make the species an easier prey or when offspring are exposed to danger due to movements or starvation. It is, therefore, important to clarify possible ecological and biological impacts of light pollution, especially regarding disturbances in protected or endangered environments, habitats and/or species. Exception from the ban can be approved if needed for public health or safety [38], enabling road lighting under certain circumstances.

Natura 2000 areas are protected in Swedish legislation and include nature reserves and national parks. These areas were chosen by the county administrative boards, reviewed by the SEPA, and the government decided which areas should be proposed for inclusion in the European Natura 2000 networks by the European Commission [41].

For protected areas, the Swedish Environmental Code (Chapter 7, Section 4) is relevant: "A land or water area may be declared a nature reserve by a county administrative board or a municipality for the purpose of preserving biological diversity, protecting and preserving valuable natural environments or satisfying the need for areas for outdoor recreation. Any area that is needed for the purpose of protecting, restoring or establishing valuable natural environments or habitats for species that are worthy of preservation may also be designated a nature reserve."

Restrictions on the right to use land and water areas that are necessary to achieve the purpose of the reserve shall be included in the decision, which gives an opportunity to restrict the use of artificial light within nature reserves. It is also possible to impose further restrictions if reasons emerge.

Swedish legislation provides a clear legal framework that the environment and species should be protected against various damaging and detrimental impacts and that protected species and animals should not be disturbed by light.

\section{Best Practice Guidelines for Outdoor Lighting within Protected or Sensitive Environments}

Outdoor lighting is sometimes required within protected or sensitive environments to ensure safe transportation and safety in general for people in those areas. However, if outdoor lighting is at high levels and a significant proportion of light spills and reflects towards surrounding areas, light pollution should be reduced. This may be especially important if the nature conservation areas were established to preserve protected species that are particularly light-sensitive or nocturnal or where there is a high risk that they will be negatively affected by predation or intra-species competition induced by light pollution. Increased protection against light pollution may apply to species of bats, amphibians, reptiles, birds, insects and certain mammals and fish.

Best practice guidelines can be divided along practical lines, such as type of light sources, shielding, limitation on upward light, lighting control and scheduling and the maximum amount of light for different functions, e.g., [16,42,43]. Previous work includes the establishment of guidelines for outdoor lighting in Dark-Sky Preserves ${ }^{\mathrm{TM}}$ by the Royal Astronomical Society of Canada (RASC) [42,44]. Best practice guidelines are based on experience and knowledge of ecological and biological impacts where even low levels of artificial light are believed to have a significant impact on animals or organisms, their night vision or the area's light pollution levels and the principle that it is possible to reduce ecological impact by adaptations to the SPD to ensure less visibility to sensitive species. General guidelines and recommendations for outdoor lighting with an enhanced focus on light pollution reductions is used in several countries around the world, for example, Austria [45]. However, general guidelines for outdoor lighting are often written without a clear focus on protected or sensitive environments, but such environments may require more strict or site-specific regulations to ensure the long-term survival of specific species. 


\subsection{Light Sources, Lighting Design and Technology}

Since animals and organisms have varying sensitivity to different light wavelengths, the ecological impact of light sources depends upon the distribution of light energy in different wavelengths, i.e., the emitted light's SPD. It has been suggested that SPD be adapted to reduce ecological impact. In general, light emitted in the blue wavelengths $(<500 \mathrm{~nm})$ may cause non-visual impact and affect circadian rhythms in vertebrates, as has been demonstrated in humans [46]. Many species have photoreceptors in the blue SPD and may, therefore, be more sensitive to those wavelengths compared with humans, including mammals [47], birds [48], insects, reptiles and amphibians [49]. It has, therefore, been suggested that wavelengths around the blue region should be filtered out, eliminated or reduced in outdoor lighting $[16,50,51]$. However, light sources with less blue light does not guarantee against ecological impacts, since organisms may still be affected.

In protected areas, white light sources, such as (phosphor-based) white light emitting diodes (LEDs) or ceramic metal halide [42] should be avoided. High-pressure sodium lamps (HPS) with yellow light are not entirely free of light below $500 \mathrm{~nm}$. However, it is recommended to use an amber LED that has slightly yellowish-coloured light with a peak at $590 \mathrm{~nm}$, where there is minimal light $<500 \mathrm{~nm}$ [42], provided that the SPD is known. It is also possible to use filters to absorb unwanted wavelengths, and another recommendation is to use filtered yellow-green and amber LEDs, since they will have a lower impact on wildlife in comparison with HPS and blue-rich lighting ( $\geq 2200 \mathrm{~K})$ [52]. IDA International Dark Sky Park Designation Guidelines restricts using lamps to below $3000 \mathrm{~K}$, or that less than $25 \%$ of the emitted light of the total spectral power distribution is below $550 \mathrm{~nm}$ [18].

The Low Impact Lighting (LIL) standard recommends using $\leq 2200 \mathrm{~K}$ and limiting the energy flux $<500 \mathrm{~nm}$ to under $6 \%$ of the total emitted light (in the visible range) [53]. However, if the average illumination is $<5$ lux, the use of $2200-2700 \mathrm{~K}$ is allowed if energy flux $<500 \mathrm{~nm}$ is $<10 \%$ of the total emitted light [53]. The illuminance of light is often estimated in lux, and by the luminous flux per unit area which is calculated based on a standardized model for human vision. Illuminance levels of about 100,000 lux can be found in full sunlight, illuminance between 0.5-30 lux at the ground can be found for road lighting, and values well below 1 lux are commonly found for moonlight and skyglow.

The use of amber LED, phosphor converted (PC) amber LED or light sources with low colour temperature does not guarantee no ecological impact on specific species, but it is likely that most species will be less affected. If the aim is to protect a targeted species, knowledge about the species' visual system, physiology and ecology must be used to choose appropriate light sources and illumination levels. Such information is available in published research studies, e.g., by Spoelstra [54].

By filtering out unwanted wavelengths, it is possible to adapt lighting to prevent adverse impact on specific species or groups of species, but impacts may still occur on species that have photoreceptors that are active in the specific wavelengths used. It is, therefore, recommended to combine adaptations in wavelengths with other measures when using artificial light in protected areas, such as shielding, scheduling, dimming and maximum light levels. Reducing artificial light in the wavelengths of visual perception of a particular species and designing the lighting system so that the light does not reach the habitats, either by direct light or indirectly by scattering light, have been shown to reduce the impacts of artificial light on the orientation of sea turtle hatchlings [55,56]. Using low correlated colour temperature (CCT) light sources and filtering the light sources dramatically reduces the lighting system's energy efficiency and increases electricity consumption. However, increased electricity use may be an acceptable compromise.

Light from a luminaire can be blocked from reaching certain angles by physical barriers attached to the luminaire, i.e., shielding. This limits the light's impact on the surrounding environment outside the target areas and reduces the affected area and the impact of glare and skyglow. In the case of LED luminaires, light distribution from the lens on the front of the LED chips can also assist. 
If LEDs are necessary, the RASC recommends a maximum of $3000 \mathrm{~K}$ in combination with reduced illumination and the use of sharp shielding (SCO, sharp cut-off) [42], such that $0 \%$ of the total luminous flux is permitted on or above the horizon and $<1 \%$ of the total luminous flux is allowed between 80 and $90^{\circ}$ above the nadir (Figure 1A). The SCO differs from the Illuminating Engineering Society of North America (IESNA) cut-off classifications (i.e., non-cut-off, semi-cut-off, cut-off and full cut-off, FCO), being stricter than the full cut-off. For FCO, luminous intensity at or above $90^{\circ}$ nadir is kept at zero, and the luminous intensity at or above $80^{\circ}$ above the nadir should not exceed $10 \%$ of the luminous flux (of the lamp).
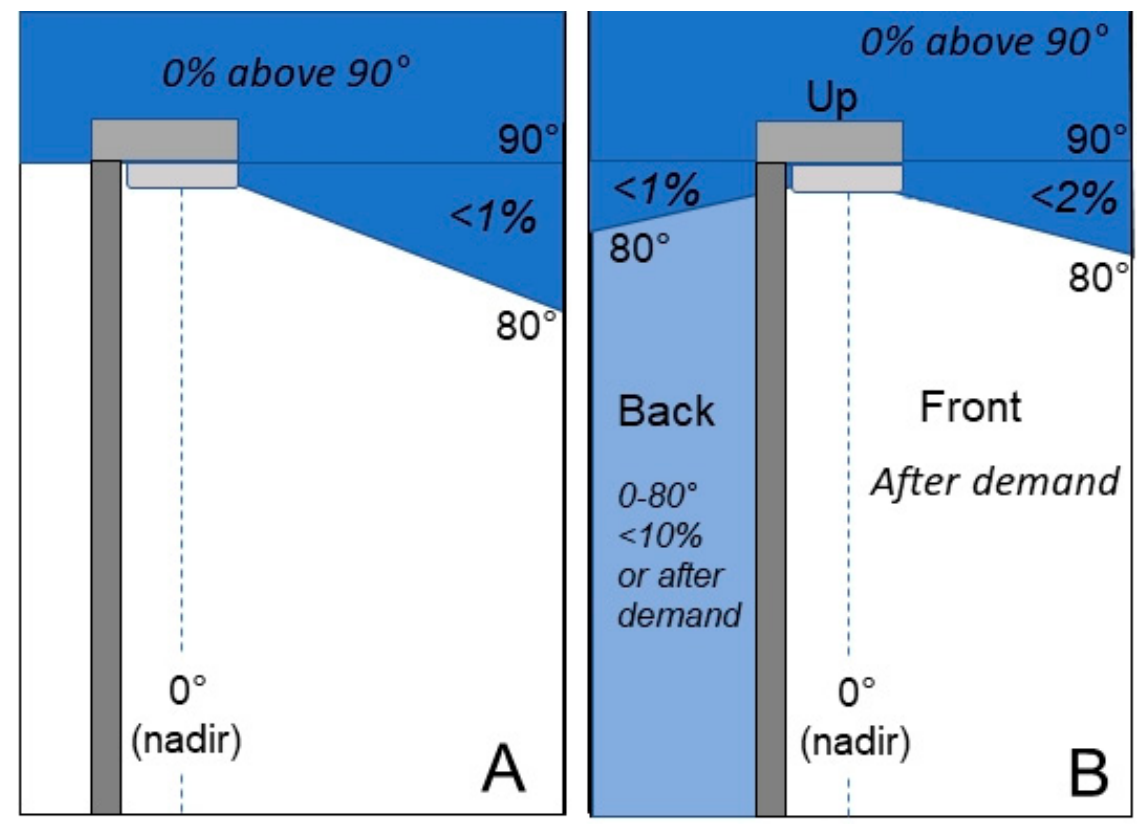

Figure 1. Examples of shielding of luminaries to reduce ecological light pollution in protected areas: (A) sharp cut-off, SCO (B) BUG system. Non-correct scales and angles.

The backlight, uplight and glare (BUG) system developed by the International DarkSky Association (IDA) [57] allows a stricter and more detailed shielding requirement for luminaires, which would be more appropriate in sensitive and protected areas. This system makes it possible to limit the amount of light at various angles from the luminaire, separated by backlight, front light and uplight. For example, it is theoretically possible to restrict the luminous flux to $0 \%$ above $90^{\circ}$, to $<1 \%$ at $80^{\circ}$ above the nadir in the backlight and $<10 \%$ in all other angles of the backlight and to $<2 \%$ at or above $80^{\circ}$ above the nadir in the front light and after demand in the other front light angles (Figure 1B). It is recommended to keep uplight at zero and backlight as low as possible in protected areas to prevent light pollution and skyglow.

White and broad-spectrum light sources enable animals and organisms to detect objects to a higher degree at night compared to light sources with limited emissions over the SPD [58]. Thus, it is reasonable that, for broad-spectrum light sources, the maximum permissible levels for the proportion of luminous flux at $80^{\circ}$ above the nadir be considerably lower than for light sources with a limited wavelength distribution, such as amber LED. However, if the initial lamp is $\leq 500$ lumens, deviations from the shielding requirements can be accepted for special purposes [18]. Assessment of skyglow in two dark sky regions of Portugal, one a national park and the other a dark sky reserve classified as a starlight tourism destination by the Starlight Foundation, showed that the contribution of skyglow from small towns was negligible and that only a few hundred metres away, the sky quality improved quickly [59]. However, skyglow from densely populated areas in the surroundings and at far distances (tens of $\mathrm{km}$ ) still contributes to light pollution in dark sky regions, even if it is weak. 
Other tools to reduce ecological light pollution with a focus on road lighting planning are exemplified by requirements related to the disability glare quantified by the Threshold Increment (TI) and the Edge Illuminance Ratio (EIR) [60]. TI and EIR are mainly used in the design and planning phases and are difficult to measure or follow up in situ. Different luminous intensity classes are also proposed in the European standard EN 13201-2, where classes $G^{*} 6-G^{*} 4$ have the lowest maximum levels of luminous intensity at $70^{\circ}$ and above [60]. EN 13201-5 also introduced specific energy performance indicators with the intention to keep lighting inside the area under illumination and keep lighting levels as close as possible to the selected lighting class to minimise the road lighting installation's energy consumption [61]. This lead, directly and indirectly, to a more precise lighting design for roads that are identified for illumination.

To reduce skyglow and obtrusive light, it is also possible to limit the upward light output ratio (ULOR), the upward light ratio (ULR) or the upward flux ratio (UFR) [62]. It is suggested that ULOR should be $0 \%$ when tested in the laboratory and that this limit be used as a requirement for road lighting procurement in the EU [63]. Installations requiring tilting should not result in direct upward light output by using appropriate optics, reflectors and lenses. The International Commission on Illumination (CIE) 150:2017 technical report [62] recommends maximum ULR values for luminaires divided by different environmental zones, from 0 for E0 and E1, 2.5 for E2, 5 for E3 and 15 for E4. However, ULR does not include light reflected from surfaces beneath the luminaire or from the surroundings; therefore, the UFR is probably more suitable when enforcing limits for skyglow and light pollution. The suggested maximum values of UFR of installations differ between road lighting (E0: not applicable; E1: 2; E2: 5; E3: 8; E4: 12), amenity lighting (E0-E1: not applicable; E2: 6; E3: 12; E4: 35) and sports lighting (E0-E1: not applicable; E2: 2; E3: 6; E4: 15). Moreover, the ULOR's maximum value can be halved when the lighting installation is on curfew [63]. The proposed measures and requirements to reduce skyglow and obtrusive light do not entirely prevent ecological light pollution, since artificial light is also reflected from roads and the surroundings. There are few studies showing the effectiveness of implementing limits for BUG, TI, ULR or UFR for reducing ecological impacts. However, clear limits that restrict artificial light from spreading or being scattered into natural areas should be used as a precautionary principle when planning lighting in sensitive areas.

\subsection{Scheduled Lighting Operations and Curfews to Support Dark Periods}

It is particularly important to schedule lighting to dim or switch off in sensitive areas, as many animals are adapted to the dark, such as nocturnal or crepuscular (active primarily in twilight and dawn) species, and are, therefore, expected to be adversely affected by the presence of artificial light. Scheduling lighting to switch off or dim to reduce lumen output also saves energy, which is generally considered positive from an energy and climate change perspective. Switching off or dimming light will create dark times in protected areas so that nocturnal or crepuscular species will most likely increase their survival rates and, hence, enhance the conservation of the species and area. Modern technology offers several solutions for controlling the switching off and dimming of lighting installations. Luminaires can be dimmed to various levels automatically via scheduled profiles or using inputs from field sensors. In LED luminaires, drivers can also be pre-programmed to follow a specific profile throughout the year without adding significant costs to the equipment itself.

Since sensitive areas require lighting for different purposes than residential areas, cities or roads where many humans travel, it is strongly recommended to introduce more strict curfews and/or switching off time periods to protect areas from unwanted light pollution. For example, the LIL standard states that all luminaires should be turned down from $100 \%$ to $10 \%$ during curfew hours (outside peak traffic hours) or at least to $50 \%$ if old technology is used [53]. For areas considered light-sensitive, outdoor lighting is recommended from dusk and when needed based on human activities in the area. Another strategy is to turn off the luminaires $2 \mathrm{~h}$ before sunrise and $2 \mathrm{~h}$ after sunset [17]. Information to the public can be provided in advance so that visitors are informed and understand why curfews 
are implemented. Curfews for parts of the street lighting and decorative façade lighting in Vienna, Austria, was observed to improve the night sky brightness by circa $1.4 \%$ when measured during one night in 2012 [64].

In areas inhabited by species that are sensitive to outdoor lighting, it is recommended to perform an investigation to find out which part of the day/night the species is active throughout the year. However, such investigations are not always possible. If the area is believed to be inhabited by light-sensitive species, artificial light should be reduced and/or switched off whenever natural darkness occurs to avoid adverse impact. Sensor-activated (adaptive) or controlled lighting is also recommended for roads or paths with little traffic, where artificial light is considered necessary for humans. Dimming schedules and sensoractivated systems should also implement recommended maximum levels of illuminance.

It is generally justified to implement dimming schedules or part-night lighting to reduce the ecological impact on species. However, part-night lighting has proved insufficient to avoid impacting light-averse bats, and such species can still be adversely affected by artificial light [65]. For example, bats' foraging time can be reduced even if lighting is dimmed during part of the dark time period. Dimming may have a smaller impact on light-aversive bat species depending on the illuminance level [66]. Very few studies have combined dimming and part-night lighting to better understand the thresholds of avoidance or attraction for light-sensitive species. Consequently, currently recommended best practice precautionary measures for light-sensitive species are to switch off lighting or implement dimming and/or part-night schedules starting as early as possible.

\subsection{Recommended Maximum Amount of Light for Different Functions}

One effective way of limiting unwanted light in protected and/or sensitive environments is to introduce maximum values based on different functions for humans $[43,53,62,67]$. For example, maximum illuminance levels can be combined with other lighting design characteristics, such as shielding, light source type and height (Table 2). Maximum illuminance levels can be regarded as recommendations from which it is possible to deviate if necessary. For cultural environments or historical sites, it is recommended to use FCO or SCO luminaire shielding and the same lighting values and light sources as nearby areas. People who visit protected areas should use torches with yellow or red light but below 300 lumens.

Table 2. Recommended lighting in sensitive areas based on functions adapted from [42]. $\mathrm{FCO}=$ full cut-off; $\mathrm{SCO}=$ sharp cut-off; $\mathrm{LED}$ = light emitting diode; $\mathrm{CMH}=$ ceramic metal halide.

\begin{tabular}{lllcc}
\hline \multicolumn{1}{c}{ Area } & Shielding & Light Source & $\begin{array}{c}\text { Maximum } \\
\text { Illuminance } \\
(\mathbf{l u x})^{*}\end{array}$ & $\begin{array}{c}\text { Pole Height } \\
(\mathbf{m})\end{array}$ \\
\hline Buildings & FCO or SCO & Amber LED & $\sim 2$ & 2.5 \\
\hline Car parks & FCO or SCO & Amber LED & $\sim 3$ & 6 \\
\hline $\begin{array}{l}\text { Paths, bicycle and } \\
\text { pedestrian lanes }\end{array}$ & FCO or SCO & Amber LED & $\sim 1$ & 1 \\
\hline $\begin{array}{l}\text { Property } \\
\text { (private and others) }\end{array}$ & FCO or SCO & $\begin{array}{c}\text { No broad-spectrum } \\
\text { LED or CMH }\end{array}$ & $<3$ & 1.5 \\
\hline Door lights & FCO or SCO & $\begin{array}{c}\text { No broad-spectrum } \\
\text { LED or CMH }\end{array}$ & $<3$ & 6 \\
\hline Garden lights & & &
\end{tabular}

* Maximum illuminance on the ground.

Maximum illuminance values are based on human visual capabilities and not perceived safety. Illuminances of 2 lux on the ground will enable most people to walk outdoors after dark and detect obstacles, thus ensuring safe movement [68]. Average illuminance of 1-3 lux on the ground and less than 3 lux at eye level is generally recommended to 
keep illuminance values the lowest possible in sensitive areas [17]. Illuminance levels on the ground between 1 and 3 lux is in line with a mean illuminance of 2-5 lux as required for some of the P lighting classes in the European standard EN 13201-2. However, older persons ( $>65$ years) with a more degraded retinal image will probably have more difficulty detecting obstacles at very low illuminance values (0.2 lux) [68], which could motivate them to use higher maximum illuminance values when visiting protected areas.

Perceived safety is strongly correlated to illuminance, and it is, therefore, suggested to evaluate lighting design between daytime and after dark [69] instead of comparing different illuminance levels in darkness. Comparisons of the perceived safety between day and dark indicated that small increases between 0 and 10 lux (median horizontal illuminances) resulted in increased perceived safety in car parks, while illuminances above 10 lux showed marginal increases in perceived safety [69]. Thus, horizontal illuminance values of 2-3 lux will ensure safe human movements, but these might be too low for perceived safety. Therefore, maximum illuminance levels in protected areas must be chosen depending on the lighting's function and location.

The LIL standard does not allow illuminations on highways or motorways, roads for motorised traffic alone or roads, junctions or roundabouts outside settlements, and the luminance of main roads in cities is not allowed to exceed luminance values of $0.5 \mathrm{~cd} / \mathrm{m}^{2}$ [53]. The LIL standard also states that the illumination of parking places on highways or roads must be kept under 1 lux. Although it is not clear whether this is a mean value or a minimum value taken anywhere on the ground surface, it can be compared with P6 in the European standard EN 13201-2 which can be applied on parking places [60]. It states that average horizontal illuminance on the ground should be 2.00 lux, and the minimum horizontal illuminance 0.4 lux.

\section{Environmental Lighting Zones}

Lighting environments can be used to classify land into zones of different character over a larger area and thus get an overview of which areas should be prioritised in strategic work with natural environments or to gain insight into which natural environments should be protected from future light pollution. Lighting environmental zones can also be used to create a framework for limiting light pollution in a municipality or a region. There are many good and practical reasons to divide an area into zones. It is, for example, easier to work with nature conservation in the planning process on a landscape level where an area is defined by environmental lighting zones. Urban development using environmental lighting zones in the planning process will quickly identify lighting needs for a range of various areas and functions.

Zone classification has been suggested by IESNA-IDA [70] and the CIE [62]. The CIE environmental lighting zones are differentiated based on the ambient brightness of the environment to be experienced and are divided into E0 to E4, ranging from intrinsically dark to high district brightness. The IESNA-IDA Model Lighting Ordinance uses lighting zones (LZ-0 to LZ-4) and recommends uses and areas, zoning considerations and ordinance text based on recommendations for lighting design and use within the lighting zones. The suggested maximum illuminance levels presented in Section 3.3 have been adapted to various environmental lighting zones [62]. The Guidelines for Outdoor Lighting (LowImpact Lighting ${ }^{\mathrm{TM}}$ ) for the RASC Dark-Sky Protection Programs mainly refer to areas LZ-0 and LZ-1.

The CIE environmental lighting zone classification is presented in Table 3. A matching description for the Bortle dark-sky scale [71] is included to make it easier to find the right zone, for example through field visits. The Bortle dark-sky scale can easily be identified using photographs and comparisons with the night sky. For knowledge of the relative brightness in an area, the web-based light pollution map [72] and the World Atlas of the Artificial Night Sky Brightness [73] can be used. The different environmental lighting zones are described below, with some consideration for ecological impact. 
Table 3. Environmental lighting zones [62] and examples of areas and the corresponding Bortle dark-sky class [71].

\begin{tabular}{llll}
\hline Zone & $\begin{array}{l}\text { Lighting } \\
\text { Environment }\end{array}$ & Examples & Bortle Dark-Sky Class \\
\hline E0 & Intrinsically dark & $\begin{array}{l}\text { IDA Dark Sky Parks, areas } \\
\text { dark enough to see the } \\
\text { Milky Way. }\end{array}$ & Class 1. Excellent dark sky. \\
\hline E1 & Dark & $\begin{array}{l}\text { Relatively uninhabited } \\
\text { rural areas. }\end{array}$ & $\begin{array}{l}\text { Classes 2-3. Dark and rural } \\
\text { with small amounts of } \\
\text { lighting. }\end{array}$ \\
\hline E2 & $\begin{array}{l}\text { Low district } \\
\text { brightness }\end{array}$ & Sparsely inhabited areas. & $\begin{array}{l}\text { Classes 4-5. Rural } \\
\text { transition and suburban } \\
\text { with little lighting. }\end{array}$ \\
\hline E3 & $\begin{array}{l}\text { Medium district } \\
\text { brightness }\end{array}$ & $\begin{array}{l}\text { Well-inhabited rural and urban } \\
\text { settlements. }\end{array}$ & $\begin{array}{l}\text { Classes 6-7. Light } \\
\text { suburban sky and } \\
\text { suburban-urban transition. }\end{array}$ \\
\hline E4 & $\begin{array}{l}\text { High district } \\
\text { brightness }\end{array}$ & $\begin{array}{l}\text { Town and city centres and } \\
\text { other commercial areas. }\end{array}$ & $\begin{array}{l}\text { Classes 8-9. City sky and } \\
\text { city centres. Very bright. }\end{array}$ \\
\hline
\end{tabular}

Zone E0-Intrinsically dark. Star visibility is not affected by any ambient lighting. Introducing artificial lighting would have severe consequences for the natural environment and ecological impact. Human use is adapted to the darkness and may, for example, include recreational activities and tourism. Zone E0 includes national parks where the visibility of the night sky is not affected by skyglow or other light sources in the surroundings. It may also include major optical observatories.

Zone E1-Dark. This zone covers relatively uninhabited areas and very dark places where lighting is occasionally scattered in the landscape or around smaller buildings and individual properties. This zone covers areas where lighting can affect flora and fauna. Humans have adapted to low light levels. Street lighting is not typical. Lighting is used for safety and functional reasons but is not placed coherently or uniformly through the landscape. In this zone, lighting should be adapted to activity levels and switched off when not required, for example, in smaller countryside towns. It is encouraged to implement control systems for road lighting or/and switch off certain types of lighting following a schedule.

Zone E2-Low district brightness. This zone covers sparsely inhabited areas that have low levels of ambient light, such as industrial or residential areas in the countryside or areas in the transition between rural areas with sporadic settlements to suburban areas. In this zone, people are accustomed to using moderate amounts of outdoor lighting, for example on residential streets, for safety, security and accessibility but also recreation. In these areas, natural environments may be between the buildings which are then exposed to light pollution. Here, too, control systems and scheduled switch-off systems can be implemented.

Zone E3-Medium district brightness. This zone includes areas in densely populated rural areas or cities with light suburban skies or areas located in the transition between the suburban and urban environments. There are relatively high amounts of lighting that are usually coherent and can also be continuous. Natural environments may be intermixed between buildings and built areas and are, therefore, usually exposed to light pollution. Even within this zone, lighting should be switched off or dimmed, especially at night when human activities are lower.

Zone E4-High district brightness. This zone includes cities and city centres and industrial areas with extensive lighting. The city sky is very bright, and the users are used to high visibility. Human activities are central to the lighting design, and very few natural environments are present in these areas. Public lighting in this zone results in much skyglow. Decreases in light pollution can take place through several measures. The lighting can be dimmed at certain times of the day and will still be perceived as safe and secure. 


\section{Species and Group Priorities}

One primary key for prioritising measures to mitigate light pollution effects is to assess how disturbances affect species' conservation status, since this varies. Unfortunately, very few existing studies on the impact of artificial lighting on fauna and flora have estimated the effects on demography, species composition or ecosystem function $[9,10]$, that is, the effects that are directly relevant from a conservation perspective. The literature provides only an estimate of impacts on species' conservation status based on the expected sensitivity or vulnerability to light [13].

Six different groups that have been identified as expected to be unusually vulnerable to ALAN may, therefore, require a higher priority when planning measures to mitigate the impact of light pollution (Table 4).

Table 4. Species and groups that may require higher prioritisation due to their increased sensitivity to light or the risk of negative influence at sensitive periods in their life cycles.

\begin{tabular}{ll}
\hline Species and Groups & $\begin{array}{l}\text { Potential Ecological Impacts of Artificial Light at } \\
\text { Night (ALAN) }\end{array}$ \\
\hline Nocturnal or crepuscular species & $\begin{array}{l}\text { ALAN can result in decreased time and area for } \\
\text { night-time activities important for survival, which can } \\
\text { result in lower fitness and survival rates. }\end{array}$ \\
\hline Vulnerable habitats & ALAN can result in an unusual high impact. \\
\hline Migrational or seasonal movements & $\begin{array}{l}\text { ALAN can result in unwanted impact on migration or } \\
\text { seasonal movements, which are vulnerable periods in } \\
\text { life cycles. }\end{array}$ \\
\hline Positive or negative phototaxis & $\begin{array}{l}\text { ALAN may cause ecological traps by attracting species } \\
\text { with positive phototaxis, resulting in high mortality. }\end{array}$ \\
\hline \multirow{2}{*}{ Endangered species } & $\begin{array}{l}\text { ALAN may decrease the species area of activities for } \\
\text { species with negative phototaxis, which can cause } \\
\text { lower fitness and survival rates. }\end{array}$ \\
\hline Key ecosystem functions & $\begin{array}{l}\text { In endangered or threatened species, ALAN may act } \\
\text { as an additional or cumulative disturbance, resulting } \\
\text { in further degradation of habitats and a potential } \\
\text { detrimental impact on species. }\end{array}$ \\
\hline
\end{tabular}

Higher risks of a negative impact can be expected in nocturnal or crepuscular. Due to the loss of darkness, nocturnal and crepuscular species' activity patterns and life history traits can be affected negatively by ALAN [74] because less time is available for activities such as foraging, reproduction, migration or movements if exposed to ALAN in their natural habitats. Correspondingly, the area available for night-time activities will also be reduced if the habitat is exposed to ALAN. Impacts include, for example, smaller foraging areas, higher competition with light-opportunistic species and increased predation risk. Many protected and endangered species are nocturnal, including bats, amphibians, certain bird species and some insect species.

Nevertheless, it might be very difficult to avoid actual impacts when planning new residential areas, for example. The influence of ALAN on amphibians in residential areas may be unavoidable, considering the myriad lighting needed for humans and the high light sensitivity of nocturnal amphibians such as frogs or toads. If the area is relatively flat, it might be impossible to keep the habitats completely undisturbed from ALAN unless light barriers are used to stop the light from entering the habitats.

Another group with high priority is found in habitats that are particularly vulnerable to light pollution. Habitats with a high frequency of light-sensitive species are more vulnerable to light emissions, even at relatively low levels, for example, aquatic environments (see Section 6). Habitats with endangered species that are light-sensitive and exposed to high levels of light pollution might be at high risk of detrimental and irreversible degradation 
when the habitats can no longer sustain the endangered species. This can be compared with lethal exposure to a threshold value, where the organism exposed can no longer survive. High levels of light pollution usually originate from poorly designed lighting and a lack of awareness of the need to protect habitats from exposure to ALAN, for example urban areas, coastal areas or areas where ALAN at a relatively high level is provided but lacks appropriate measures to minimise light pollution and spills light into the habitat. An example is when protected areas are intermixed with the built environment, so that species like bats, amphibians or insects are using urban green areas as habitats.

Species that migrate or make seasonal movements, either by air or on land, may be especially sensitive to artificial light. This sensitivity arises since certain species orient with the help of the night sky, which can be more difficult with increased sky brightness, and because migration is one of the most critical stages in the annual cycle of migratory birds. Birds that migrate in darkness are susceptible to light sources and may be attracted to fire or artificial light. It is well known that artificial light attracts migrating birds and seabirds who become disoriented. Globally, it has been shown that light pollution was greatest within migration passages for nocturnally migrating birds and that the impact of ALAN was larger for short-distance migrants and for species with smaller ranges [75].

Impact on flying behaviour can lead to collisions and bird death due to attraction to light [76]. Birds' attraction to light has been known for a very long time (hundreds of years, probably even longer) when it was observed that birds, especially in fog, are attracted to the glow of lighthouses along coasts and become confused by the light. This can cause birds to fly in circles and collide with structures or die from exhaustion [77,78]. Additionally, buildings, windows and communication towers that are illuminated can lead to high numbers of dead birds [79,80]. Light attraction at sea can reach up to ca. 3-5 km from the source of origin [81].

Movement responses triggered by light in the environment are called phototaxis in animals [82]. Phototaxis can be positive, which is a movement towards the light stimulus, or negative, which is a movement away from the light stimulus. Species that exhibit positive or negative phototaxis are considered sensitive to artificial lighting. The ecological impact of phototaxis can be negative or positive, depending on the species. For example, frogs, birds and insects that are attracted to artificial light are exposed to a higher risk of predation, while light-opportunistic bat species increase their foraging in artificial light. When artificial light creates an ecological trap for organisms, it may reduce species' survival rates because species are attracted to areas with higher predation or injury risks. For example, attraction to road lighting will expose animals or insects to an increased risk of being hit by a motor vehicle, taken by predators or dying in other ways, e.g., [83,84]. Another example of an ecological trap is when artificial light is reflected in polarising surfaces (e.g., asphalt or cars), which is very attractive for polarotactic aquatic insects and will result in insects that mate, settle, swarm and oviposit in the polarising surfaces and not in water bodies [85]. Species with negative phototaxis or light aversion will avoid areas with artificial light and thereby reduce their area or home range for foraging or commuting. This might apply to, for example, the lesser horseshoe bat (Rhinolophus hipposideros), which has been shown to prefer commuting routes with illuminance levels of ca. 0.04 lux [86]. Species might seek refuge in the landscape to get protection from light by utilising forests or another structure that functions as a light barrier [87].

Species that are endangered or threatened due to anthropogenic activities are expected to suffer from light pollution. It is likely that additional or cumulative disturbances, such as ALAN, may result in extra deterioration of habitats and ecosystems, which may result in critical conditions for species survival, especially if the species are vulnerable for ALAN.

Ecosystem functioning can be affected by artificial light, with serious consequences for habitat and ecosystem conservation. For example, pollination by nocturnal insects can be affected $[15,88]$, resulting in disrupted pollen transport. Indirect consequences of artificial light include the attraction of certain fast-flying bat species that feed on a large number of insects around the light sources $[89,90]$. The competitive advantage of certain bat 
species may lead to an unwanted impact of light-averse bat species, e.g., [91] and should be seriously considered when aiming at conserving endangered species in light-polluted areas. Artificial light can affect the ecosystem through different changes in trophic interactions, which may, in turn, affect ecosystem services.

Measures to limit the negative effects of lighting should be prioritised in areas inhabited by species that are considered light-sensitive, especially if the areas contain reproductive or resting places. The fact that a species is threatened or endangered should also weigh heavily in the context since it is in these species, especially if they are also well known to be vulnerable to ALAN, that one can expect the strongest and fastest effects.

\section{Sensitivity of Environments and Ecosystems to Light Pollution}

In this section, the sensitivity of different environments will be discussed based on lighting conditions, ecological relevance and impact and the aspects that should be considered in lighting planning.

\subsection{City Centres and Towns}

Heavily built-up environments, such as city or town centres, usually have many luminaires to support active around-the-clock human life, with high illuminance and many light sources, from road lighting to commercial lighting. In central urban environments, there are few light-sensitive or protective species, but there may be habitat networks of trees or vegetation that support connectivity, for example between parks and other green areas. Consequently, green infrastructure and surfaces such as parks and street trees may need protection from light to function as refuges or habitats for insects, animals and organisms whose rhythm is dependent on periods of darkness. Insects found in city environments or adjacent areas that exhibit positive phototaxis have a high risk of being eradicated due to the vacuum cleaning effect. There is an increased risk of ecological impact in rivers or streams passing through central urban areas that may affect ecosystem habitats upstream and downstream or the predator-prey balance in lakes. This should be especially considered if there are protected fish or other organisms in the water (both migratory and stationary species).

City centre lighting and skyglow risk attracting migrating wild birds that collide or continuously circle around high structures, such as buildings, towers, masts, installations or aesthetic lighting. Precautionary principles should be implemented to avoid adverse impacts on wild birds (in time, space and/or wavelengths). It should be ensured that tall buildings do not use wavelengths or technology that attract birds. The lighting should be limited in strength and illumination because light in the sky is visible from very long distances. The attractiveness of the lighting can be further enhanced by overcast skies, resulting in increased bird mortality [92]. Using light on high buildings and towards the sky in open environments such as water or in open cultural landscapes where the light is not physically stopped by objects such as buildings, trees, mountains, etc. can, therefore, reach very far in the terrain and attract birds from natural environments that are not illuminated. The lighting in cities causes skyglow and impacts natural environments several kilometres or tens of kilometres from the city centre. It cannot be ruled out that many light-sensitive species, such as species of birds, amphibians and bats, can be affected by skyglow.

\subsection{Urban Environments}

Urban environments are characterised by a high density of buildings and residences, can be located on the outskirts of cities, and are often adjoined by natural environments or water. Lighting levels are not as intense as in city centres, but lighting is an important aspect for human well-being as many people live in urban environments. Lighting is available in, for example, residential environments, on transport routes, in shops, sports facilities and industries and in connection with natural environments for outdoor activities and recreation. The variation in illuminance is high because of numerous lighting needs, including sports lighting and aesthetic lighting in private gardens. 
There are species and animals in illuminated urban environments that can exploit the presence of artificial light in natural environments, such as birds and spiders that can benefit from prolonged feeding time or be protected from natural predators that avoid light. Insects in natural environments that are attracted to lighting will accumulate and die or become prey. Light-opportunistic bats can benefit indirectly from lighting by increasing foraging.

Urban environments often have natural environments in their surroundings, or natural environments are scattered among or mixed up with the built environment. Thus, there are areas without any lighting. The risk of ecological impact is greater when illuminated areas are mixed with natural areas, since the edge zone is increased, and light will thus affect larger areas. Still, this also depends on environmental factors, such as objects that prevent light from spreading too far into the surroundings.

As in city centres and towns, there is a risk of attracting migrating birds to powerful or highly placed lighting [67], and the impact on organisms in aquatic environments is also important to consider. Again, it is possible that skyglow can affect species in natural surroundings, and it must be especially considered for protected areas and species.

Planning of urban environments needs to consider people's safety needs and ensure that light does not adversely affect protected species or habitats. Under certain circumstances, this may be difficult, such as when recreational sites are situated close to protected areas but also when linear transport corridors are constructed that cut through protected areas and green areas and create barriers for light-averse species. Although most species can avoid illuminated areas, the barriers can limit their home ranges and feeding areas.

Generally, in urban environments, lighting design must consider both human needs and potential negative impacts on protected species. Uplights should be avoided, and stricter shielding is recommended if luminaires are close to protected areas. Adaptive road and facilities lighting (with dimming and switch-off schedules) should be implemented as widely as possible. Outdoor lighting should have minimal glare and low content on the spectral region below $500 \mathrm{~nm}$. Protected areas adjacent to urban environments need to fully ensure that there are no significant ecological impacts on protected species; if so, mitigating measures must be developed and implemented.

\subsection{Rural Areas}

Rural areas contain a large proportion of natural environments or farmland mixed with a high diversity of buildings, individual properties and smaller villages. Many animals and organisms in rural areas are sensitive to artificial light, and they may have protection status. Artificial light will reach various distances from the light source, depending on the topography and the landscape characteristics.

In rural areas, lighting in smaller towns or communities is particularly important to ensure human accessibility, liveability and security. In their properties, residents need good visibility to be active outdoors during the winter or evenings and for safety reasons. The risk of causing skyglow is lower, since many installations consist of individual luminaires, but rural areas may still be affected by skyglow from adjacent urban environments or cities. Linear lighting (such as road lighting) can constitute barriers for smaller animals in rural towns or industrial areas.

The vacuum cleaning effect (for certain insects) is probably high in the countryside if outdoor lighting is on high poles, when the light can reach far into the landscape, for example in agricultural areas. In open landscapes, light can spread very far from the light source, since obstacles are limited, causing insects from the surrounding environment to gather in high density around the luminaires. However, in forest rural areas, the impact of far-reaching light and the vacuum cleaning effect are expected to be lower.

Natural environments in the countryside have naturally low light intensities, and most night light comes from the starry night sky or reflection from the moon. Due to the contrast, any artificial light and light pollution will appear stronger than in the urban environment. Since many mammals in rural areas are nocturnal or crepuscular, with a higher sensitivity for seeing light in the dark, they can be affected to a greater extent when the difference 
in light intensity becomes high. Countryside lighting should preferably be minimised in illuminance levels, exposure area and time in use to be in line with precautionary principles and to better mimic natural lighting patterns and levels. Protected areas in rural areas need to ensure that artificial lighting as local light sources, regional light pollution or temporary light disturbances do not affect species in a way that significant environmental impact arises. Lighting in rural areas should be avoided at high elevations or against the sky due to the risk of impact on the many species that inhabit the rural environments.

\subsection{Forest Ecosystems}

Most forest ecosystems are located in rural areas, but forests may be near or in urban environments and cities. In forest ecosystems, species live on or in the ground and in the trees and shrubs. Species such as amphibians and nocturnal and crepuscular mammals have adapted to an environment that is considerably darker than more open landscapes. The forest is a complex structure that filters out light such as sunshine and moonlight as light passes through leaves, needles and branches, which means that even artificial light will be filtered off in forest environments. For example, natural lighting intensities in deciduous forests can range from an average of 100 lux during the evening to below 0.0001 lux during the darkest night hours [93]. Tree-living insects and species adapted to naturally low light levels are very likely to be sensitive to artificial light, especially if they nest in trees or bushes exposed to artificial light, since such conditions can directly impact their survival. For diurnal species, circadian rhythm can be affected by artificial light, as has been shown in birds, e.g., [94], while nocturnal species, including bats and smaller rodents such as mice $[12,95]$ try to avoid the illuminated area as much as possible to avoid higher predation risk.

\subsection{Aquatic Environments}

Areas close to aquatic environments are often illuminated because buildings located near water have historically been attractive, and it is popular to live close to water. Other activities may also cause light pollution in aquatic environments, such as shipping and maritime transport, ports and oil rigs [3,96]. Light sources that emit light towards water surfaces will increase the relative light levels in the surroundings due to the light's reflection and scattering in the water. Aquatic environments around buildings and built areas can be exposed to more light, both directly and indirectly. Light will spread far over water if no physical structures hinder the light. Consequently, artificial light in aquatic areas can reach and affect considerably larger areas compared to lighting in other environments. The ecological impact of artificial light in coastal areas includes, for example, increased visibility for predator fish, affecting the predator-prey balance [12,67].

Urban environments and cities commonly include aquatic elements and habitats (natural or artificial) for aesthetic, recreational or other reasons such as water collection or purification. In such areas, skyglow can lead to constant exposure to higher lighting levels than those normally found under natural conditions in similar environments [93,97].

Several types of aquatic animals and organisms exhibit high sensitivity at low illuminance and have responses such as phototaxis or photophobia, which may affect their survival. The responses are dependent on the illuminance, the SPD, the water's filtering properties and the species' ecology and depth, which makes it almost impossible to predict the effects and consequences of artificial light on species and ecosystems. However, scientific experiments have shown that there is an impact on the circadian rhythm on fish at illuminances (1 lux) that occur in indirectly illuminated environments [98,99]. Fish can be affected by an illuminance of 0.00001 to 1 lux, depending on species and behaviour [100]. For example, salmonid fish (that are sometimes protected) can be affected by road and bridge lighting such that survival can be affected [2]. Other sensitive species are amphibians bound to aquatic habitats and environments in their life cycle, bats (which may use aquatic areas for foraging) and protected species generally linked to aquatic environments, 
including many birds. A global survey of marine protected areas showed that artificial light was widespread [23].

In general, artificial light at coasts and beaches should be minimised, as these environments propagate light in the landscape and over the water. Light pollution at and in water is easy to avoid through technology and design. If there are protected species or areas in aquatic or near-aquatic environments, all artificial lighting on the water surface should be avoided, since this is the only safe way to ensure that no ecological impact occurs in any organisms.

\section{Landscape Ecology and Artificial Lighting}

Working with night-time landscape patterns (nightscapes) can improve the conservation of protected areas and species. This requires knowing which species inhabit different areas in the landscape, what habitats and natural values are prioritised for protection and how artificial light may influence species survival. The research area of nightscapes and light pollution mapping and its consequences on protected species has not received much attention but see $[101,102]$. However, based on geographically based work and species protection, it is possible to identify some important aspects and concepts to include in ecological landscape analysis of artificial light and its impact:

- Area brightness. The first approach is to quantify and classify areas by ambient brightness and/or luminance levels. Protected natural environments exposed to artificial lighting need to be surveyed and the proportion of brightness quantified by, for example, on-site measurements (see Section 8). It is possible to use various data on light pollution [103] or develop maps with more local information, see e.g., [102]. It is also important to consider skyglow and predicted changes in lighting strategies in the investigation area.

- Light inflation. As both newly built and existing built areas usually increase lighting amount and use over time, it is useful to consider light inflation in the investigation area. It is likely that field measurements or maps at the landscape level will age relatively quickly (unless local regulations are introduced to limit light pollution).

- Dead ecological zones. These are areas that cannot be used by some species because they are over-illuminated or because they are isolated geographically, for example, by continuous light barriers.

- Vacuuming cleaner effect. This effect arises because some species, such as moths and birds, can be attracted to very low amounts of light at very long distances and will disappear from these areas and concentrate in light-intensive areas [104]. Luminaires with high wattage situated high above the ground, such as sports lighting, floodlights, car park lighting or shopping centre lighting, may induce the vacuum cleaner effect over large areas.

- Barrier effects. When exterior lighting is used to create continuous paths or transport corridors for humans, the lighting causes barriers for species requiring darkness to migrate or forage. Continuous and linear light barriers can be found when road or street lighting separate habitats and their connectivity so that animals or organisms cannot cross due to light avoidance or aversion, e.g., [105].

- Migration distance and habitat network. An essential landscape quality is that endangered species can survive and disperse between habitats, thus spreading through a habitat network. If the migration distance is known, it is possible to model habitat networks for sensitive species in geographically based information systems to ensure protected habitats are connected and not separated by light barriers.

- Dark areas. There are many benefits in identifying and ensuring the conservation of dark areas, since darkness is a time for rest and recovery in organisms with circadian rhythms and because dark areas support nocturnal or crepuscular organisms' activity and survival.

- Buffer zones. Protected or sensitive environments may require extra protection in the form of buffer zones with restrictions on outdoor lighting if there is a risk of 
ecological impact from light [21] or stated requirements to reduce light pollution at the landscape level.

- Water environments. Water surfaces and shiny surfaces reflect light and can have higher luminance and ecological impact than other surface types. The influence of artificial light from static or permanent lighting in such areas could also be higher compared with other natural environments, since there are also other disturbances occurring, such as motor vehicles and their lighting.

It might not be enough to map the nightscape based solely on lighting levels, but it can also be important to estimate how much light is perceived by the species. In a study using satellite images that measured artificial light and modelled how seabird fledglings saw it on a Hawaiian islands, there were few or no areas of the island where the fledglings could fly without seeing light during their nocturnal flights [106]. Nightscape models and analyses that include the impact of artificial light on species, their visual perceptions and their need for dark areas will be useful to ensure species and habitat protection.

\section{Measuring the Ecological Impact of Artificial Light}

Lighting measurements in the field are essential for quantifying the illumination level in the area under investigation. However, to assess the ecological impact of artificial light on a specific area or habitat, this impact should be linked with a specific threshold or multiple thresholds in visible and perhaps non-visible radiation. The variety of species that may be affected by artificial light leads to a very challenging task in cases where their typical location, field of view and spectral sensitivity of their light-sensitive receptors should be considered. Field measurements are typically performed at night or in twilight under various weather conditions and can include point measurements, multiple sets or long-term monitoring campaigns.

\subsection{Current Methods}

Studies on the ecological impact of light pollution have been carried out by scientists from many disciplines using different research methods, instruments and assessment strategies [107]. In most studies, the dominant quantity measured and communicated is horizontal illuminance. It is also often accompanied by measurement or estimation of the colour temperature of the corresponding light sources. Therefore, the most used instruments are handheld illuminance meters (or luxmeters) that measure the amount of light that falls on an area. Although illuminance and CCT are widely known and used, it is questionable whether they are adequate for the quantitative and qualitative assessment of the environmental impact of artificial light. Luxmeters are designed to match the human eye's spectral sensitivity (photopic vision), and they are equipped with a dedicated filter $(\mathrm{V}(\lambda))$. While this type of instrument is excellent for assessing human-related visual tasks, in most cases it limits assessment of the impact of light on species with radically different spectral sensitivities. In addition, estimation of the spectral content of the light sources is done using the CCT of the source (either using the provided technical data or by observing the source directly). This technique may result in a misleading estimation of the SPD since the CCT is not a binding metric to the spectral content. More specifically, the same CCT can be produced using different SPDs, which is akin to trying to estimate a black box's contents by knowing only its total weight.

Another commonly used method is remote sensing data, mainly wideband radiance maps and red/green/blue (RGB) photos from the International Space Station. Both sources include valuable data regarding the spatial distribution of the illuminated areas and an estimation of the illumination levels. The main drawback is that the recorded information concerns only the direct upward radiance or reflected upward radiance for the Earth's surface without any indication of the three-dimensional propagation of the light in the area under investigation. Several estimation methods can be used, but the uncertainty is considered very high [108]. 
Regarding skyglow measurement, two dominant techniques are used: a broadband single-value light-sensitive instrument (the Sky Quality Meter [SQM]) or commercial RGB imaging cameras with various objective lenses (commonly fisheye). Both instrument types are reported in astronomical units (i.e., magnitude per arcsec square) but use sensors with completely different spectral responsivities. In addition, none of these instruments have standardised spectral responsivities nor does the reporting quantity belong to the International System of Units (SI), and thus the conversion of their measurements to SI and the traceability of their measurements is impossible [108]. This introduces uncertainty in the measurement and intercomparison of night-sky brightness. The same issue arose with measurements using wideband satellite imaging sensors and RGB commercial cameras. Although an extensive database of measurements of skyglow from SQMs and upward radiation from satellite images exists, their validity and consistency are subject to the spectral responsivity of the instrumentation and the measurement conditions used. It is, therefore, essential to establish a standardised methodology for the measurement of light pollution aspects based on the SI system that can cover the whole visible spectrum and beyond.

\subsection{Recommendations for Field Measurements}

Field measurements in sensitive and protected areas should be carefully designed and performed in accordance with the species under investigation and given the special characteristics of the area or habitat. Researchers should investigate and quantify the propagation of visible radiation towards the habitats, the quantity of radiation reaching a selected area and this radiation's spectral content. In other words, the assessment should ideally include a combination of spectral radiance and spectral irradiance. Irradiance is defined as the total spectral power that reaches an area, while radiance is linked to the directionality of light towards the area under investigation. The location of the measurement must be carefully selected as the representative location of the species under investigation. Several measurement locations may form an assessment grid. The direction of measurements and the field of view should follow the species under investigation. For example, in an investigation of the impact of artificial light on bird nests located in trees, measurement of the horizontal illuminance at ground level gives no valuable data and can lead to erroneous results. In this example, horizontal and vertical spectral irradiance and perhaps the spectral radiance of a visible light source should be recorded.

Since the use of specialised instruments for spectral measurements in the field may be expensive and complicated, instruments with dedicated spectral responsivities can be used instead. In this case, the responsivity of the measurement device should be appropriate for the task, matching the approaching sensitivity of the species to various wavelengths in the visible or near infrared and ultraviolet range. For example, instruments matching the CIE XYZ standardised curves that cover (in parts) the whole visible spectrum can be used in many cases. Location- or direction-specific measurements can be performed with instruments placed in several positions (handheld instruments) or using aerial solutions like unmanned aerial systems [109]. Users should always be aware of instrument limitations, such as the measuring range, repeatability and field of view, as well as parameters that may significantly affect their performance, such as temperature and humidity. In all cases, measurement uncertainties should be estimated and reported accordingly.

\section{Conclusions}

Ecological impact of artificial light can be expected to various extents in natural environments, but not all environments have equal importance regarding biodiversity and conservation. Priority should be given to areas and species that relevant organisations and authorities have reported as endangered or threatened on the Red List and in Natura 2000 areas. Even so, not all protected areas will suffer from exposure to artificial light since it depends on the location and what species inhabit the areas. In this paper, a proposal to prioritise species and habitats is suggested and includes nocturnal or crepuscular 
species, species in habitats particularly vulnerable to light pollution, species that migrate or have seasonal movements, species that exhibit positive or negative phototaxis, currently endangered species and species with important ecosystem functions. Initially, sensitive areas, conservation areas and areas of importance for particularly sensitive species could be prioritised for measures to minimise the negative effects of artificial lighting on biodiversity. This is most easily done by classifying natural environments that are protected into different zones and applying more constrained principles to limit lighting and light pollution. Furthermore, the light pollution sensitivity of various environments and ecosystems suggests that different mitigation strategies and adaptations should be used, depending on landscape characteristics, species sensitivity and other factors that may determine whether artificial light may induce detrimental impacts.

It is currently unclear whether the different measures presented in this paper are enough to limit possible adverse impacts on species that exhibit high sensitivity to light or negative or positive phototaxis. Such species may be affected by skyglow, especially species sensitive enough to be significantly affected by moonlight. The cumulative impact of ALAN involves skyglow and regional light pollution, which must be considered synchronously with lighting design in the planning process. However, it seems that this is seldom done when planning outdoor lighting installations. For example, in Sweden, many municipalities have "lighting programmes" as steering documents for outdoor lighting, but these do usually not include current light pollution, sustainability or environmental impact of light or how to protect natural areas from artificial light [110]. For species that exhibit high sensitivity to light or negative or positive phototaxis, it is likely that more adaptive measures are required in combination with important aspects from a landscape and conservation perspective. For example, one should include the occurrence of artificial light and its influence as an important part of action plans and conservation plans for species, habitats and protected natural environments.

For the ecological impact of species, it is well known from the scientific literature that artificial light has or can have an ecological impact that may affect survival negatively, but it is rarely known where the limit exists in more practical terms, such as illuminance levels, spectral wavelength distribution, areal distribution or species survival. Considering that it is often inappropriate to conduct experiments of ecological light impact on endangered species, precautionary principles should be applied to minimise the intrusion of artificial light at all angles in environments where such species occur. For migratory and endangered species such as mammals, birds, amphibians, and fish, artificial lighting in their home areas and migration routes should be strictly limited or avoided. However, it is not always possible to know where protected species have their home areas and migration routes without field investigations. It will be challenging to know which species are exposed to outdoor lighting. Such challenges that are difficult to overcome lead to the conclusion that light restriction measures should be implemented at a more general level to avoid negative ecological impacts on protected and migratory species.

To support the quantification of the impact of artificial light, the proposal and setting of quantitative thresholds and the monitoring of illumination levels, field measurement should be carefully designed and performed using appropriate instrumentation, techniques and methods. Research results and assessment campaigns should be supported by lighting measurements based on a standardised metrology system using instruments traceable to SI. Accordingly, all measurements will be consistent, comparable and easily validated.

Author Contributions: Conceptualization and writing original draft preparation (except Section 8), reviewing and editing Section 8, A.K.J.; writing first draft of Section 8 and review and editing other sections, C.A.B. All authors have read and agreed to the published version of the manuscript.

Funding: This research was funded by the Swedish Transport Administration, and the Swedish Transport Agency, grant number TRV2016/87245 and Bertil \& Britt Svenssons stiftelse för belysningsteknik under the project "LED-belysningens effekter på djur och natur 2016-2017". 
Conflicts of Interest: The authors declare no conflict of interest. The funders had no role in the design of the study; in the collection, analyses, or interpretation of data; in the writing of the manuscript, or in the decision to publish the results.

\section{References}

1. Beier, P. Effects of artificial night lighting on terrestrial mammals. In Ecological Consequences of Artificial Night Lighting; Rich, C., Longcore, T., Eds.; Island Press: Washington, DC, USA, 2006; pp. 19-42.

2. Hölker, F.; Wolter, C.; Perkin, E.K.; Tockner, K. Light pollution as a biodiversity threat. Trends Ecol. Evol. 2010, 25, 681-682. [CrossRef]

3. Longcore, T.; Rich, C. Ecological light pollution. Front. Ecol. Environ. 2004, 2, 191-198. [CrossRef]

4. Hölker, F.; Moss, T.; Griefahn, B.; Kloas, W.; Voigt, C.C.; Henckel, D.; Franke, S.; Uhrlandt, D.; Fischer, J.; Klenke, R.; et al. The Dark Side of Light: A Transdisciplinary Research Agenda for Light Pollution Policy. Ecol. Soc. 2010, 15, 13. [CrossRef]

5. Kyba, C.C.M.; Kuester, T.; Sánchez de Miguel, A.; Baugh, K.; Jechow, A.; Hölker, F.; Bennie, J.; Elvidge, C.D.; Gaston, K.J.; Guanter, L. Artificially lit surface of earth at night increasing in radiance and extent. Sci. Adv. 2017, 3, e1701528. [CrossRef]

6. Bennie, J.; Duffy, J.P.; Davies, T.W.; Correa-Cano, M.E.; Gaston, K.J. Global trends in exposure to light pollution in natural terrestrial ecosystems. Remote Sens. 2015, 7, 2715-2730. [CrossRef]

7. Rich, C.; Longcore, T. Ecological Consequences of Artificial Night Lighting; Island Press: Washington, DC, USA, 2006.

8. Kempenaers, B.; Borgström, P.; Loës, P.; Schlicht, E.; Valcu, M. Artificial night lighting affects dawn song, extra-pair siring success, and lay date in songbirds. Curr. Biol. 2010, 20, 1735-1739. [CrossRef]

9. Gaston, K.J.; Bennie, J. Demographic effects of artificial nighttime lighting on animal populations. Environ. Rev. 2014, 22, 323-330. [CrossRef]

10. Sanders, D.; Kehoe, R.; Tiley, K.; Bennie, J.; Cruse, D.; Davies, T.W.; van Frank Veen, F.J.; Gaston, K.J.; Tiley, K. Artificial nighttime light changes aphid-parasitoid population dynamics. Sci. Rep. 2015, 5, 15232. [CrossRef] [PubMed]

11. Swaddle, J.P.; Francis, C.D.; Barber, J.R.; Cooper, C.B.; Kyba, C.C.M.; Dominoni, D.M.; Shannon, G.; Aschehoug, E.; Goodwin, S.E.; Kawahara, A.Y.; et al. A framework to assess evolutionary responses to anthropogenic light and sound. Trends Ecol. Evol. 2015, 30, 550-560. [CrossRef] [PubMed]

12. Schroer, S.; Hölker, F. Impact of lighting on flora and fauna. In Handbook of Advanced Lighting Technology; Karlicek, R., Sun, C.-C., Zissis, G., Ma, R., Eds.; Springer International Publishing: Cham, Switzerland, 2016; pp. 1-33.

13. Jägerbrand, A.K. LED-belysningens effekter på djur och natur med rekommendationer: Fokus på nordiska förhållanden och känsliga arter och grupper; Calluna AB: Nacka, Sweden, 2018.

14. MacGregor, C.J.; Pocock, M.J.O.; Fox, R.; Evans, D.M. Pollination by nocturnal Lepidoptera, and the effects of light pollution: A review. Ecol. Entomol. 2015, 40, 187-198. [CrossRef]

15. Knop, E.; Zoller, L.; Ryser, R.; Gerpe, C.; Hörler, M.; Fontaine, C. Artificial light at night as a new threat to pollination. Nature 2017, 548, 206. [CrossRef]

16. Gaston, K.J.; Davies, T.W.; Bennie, J.; Hopkins, J. Reducing the ecological consequences of night-time light pollution: Options and developments. J. Appl. Ecol. 2012, 49, 1256-1266. [CrossRef]

17. Dick, R. Scotobiology. In Special Issue "Environmental Impact of Light Pollution and its Abatement"; Special Report of the Journal of the Royal Astronomical Society of Canada; 2012; Volume 106, pp. 7-10. Available online: https://www.yumpu.com/en/ document/view/52811576/environmental-impact-of-light-pollution-and-its-abatement (accessed on 1 February 2001).

18. IDA. International Dark Sky Park Program Guidelines. Available online: https://www.darksky.org/wp-content/uploads/2018 /12/IDSP-Guidelines-2018.pdf (accessed on 11 May 2021).

19. Cinzano, P. Laws Against Light Pollution in Italy. Available online: http://www.lightpollution.it/cinzano/en/page95en.html (accessed on 25 May 2021).

20. IUCN. About Protected Areas. Available online: https://www.iucn.org/theme/protected-areas/about (accessed on 5 April 2021).

21. Gaston, K.J.; Duffy, J.P.; Bennie, J. Quantifying the erosion of natural darkness in the global protected area system. Conserv. Biol. 2015, 29, 1132-1141. [CrossRef]

22. Newport, J.; Shorthouse, D.J.; Manning, A.D. The effects of light and noise from urban development on biodiversity: Implications for protected areas in Australia. Ecol. Manag. Restor. 2014, 15, 204-214. [CrossRef]

23. Davies, T.W.; Duffy, J.P.; Bennie, J.; Gaston, K.J. Stemming the tide of light pollution encroaching into marine protected areas. Conserv. Lett. 2016, 9, 164-171. [CrossRef]

24. Directive 2011/92/EU of the European Parliament and of the Council of 13 december 2011 on the assessment of the effects of certain public and private projects on the environment. Off. J. Eur. Union 2012, L 26, 1-21.

25. Directive 2001/42/EC of the European Parliament and of the Council of 27 june 2001 on the assessment of the effects of certain plans and programmes on the environment. Off. J. Eur. Union 2001, L 197, 30-37.

26. European Commission. Environmental Assessment. Available online: http://ec.europa.eu/environment/eia/index_en.htm (accessed on 5 April 2021).

27. Council Directive 92/43/EEC of 21 May 1992 on the Conservation of Natural Habitats and of Wild Fauna and Flora. Off. J. Eur. Communities 1992, L 206, 7-50. 
28. Directive 2009/147/EC of the European Parliament and of the Council of 30 November 2009 on the Conservation of Wild Birds. Off. J. Eur. Union 2010, L 20, 7-25.

29. European Commission. The EU's Protected Areas Natura 2000. Available online: http:/ / ec.europa.eu/environment/basics/ natural-capital/natura2000/index_en.htm (accessed on 15 April 2021).

30. European Commission. European Red List. Available online: http://ec.europa.eu/environment/nature/conservation/species/ redlist/index_en.htm (accessed on 15 April 2021).

31. Kamrowski, R.L.; Limpus, C.; Moloney, J.; Hamann, M. Coastal light pollution and marine turtles: Assessing the magnitude of the problem. Endanger. Species Res. 2012, 19, 85-98. [CrossRef]

32. Witherington, B.E.; Martin, R.E. Understanding, Assessing, and Resolving Light-Pollution Problems on Sea Turtle Nesting on Beaches; Florida Marine Research Institute: St Petersburg, FL, USA, 2000; pp. 1-73.

33. Schroer, S.; Huggins, B.J.; Azam, C.; Hölker, F. Working with inadequate tools: Legislative shortcomings in protection against ecological effects of artificial light at night. Sustainability 2020, 12, 2551. [CrossRef]

34. SFS. Lagen om byggande av järnväg (1995:1649); Infrastrukturdepartementet RST TP: Svensk författningssamling, 1995.

35. SFS. Väglag (1971:948); Infrastrukturdepartementet RST TP: Svensk författningssamling, 1971.

36. SFS. Miljöbalk (1998:808); Miljödepartementet: Svensk författningssamling, 1998.

37. SFS. Plan- och bygglag (2010:900); Finansdepartementet SPN BB: Svensk författningssamling, 2010.

38. SFS. Artskyddsförordning (2007:845); Miljödepartementet, Svensk författningssamling, 2007.

39. Naturvårdsverket. Handbok för Artskyddsförordningen. Del 1 Fridlysning och Dispenser. Available online: https://www. naturvardsverket.se/Documents / publikationer/978-91-620-0160-5.pdf (accessed on 25 May 2021).

40. ArtDatabanken. Rödlistade arter i Sverige 2015; ArtDatabanken SLU, Uppsala, 2015. Available online: https://pub.epsilon.slu.se/ 12339/1/R\%c3\%b6dlistan_2015.pdf (accessed on 1 February 2001).

41. Naturvårdsverket. Vad är Natura 2000. Available online: http:/ /www.naturvardsverket.se/Var-natur/Skyddad-natur/Natura2000/ (accessed on 25 May 2021).

42. Dick, R. Guidelines for Outdoor Lighting for Low-Impact Lighting. Available online: https://www.thelandbetween.ca/wp-content/ uploads/2016/01/guidelines-for-outdoor-lighting-1.pdf (accessed on 25 May 2021).

43. Dick, R. Guidelines for Outdoor Lighting in Dark-Sky Preserves (RASC-DSP-GOLl). Adopted by the RASC March 2008. Revised Summer 2013. Available online: http://www.rasc.ca/sites/default/files/RASC\%20DSP\%20GOL\%20-\%20Summer\%202013_0.pdf (accessed on 25 May 2021).

44. RASC; Dick, R. Guidelines for Outdoor Lighting (Low-Impact Lighting) for RASC Dark-Sky Protection Programs; Royal Astronomical Society of Canada: Toronto, ON, Canada, 2018. Available online: https://www.rasc.ca/sites/default/files/RASC-GOL_2018.pdf (accessed on 25 May 2021).

45. Bierbaum, H.; Donat, M.; Doppler, W.; Juhasz, P.; Heilig, P.; Holzer, E.; Rudolf, H.; Erwin, H.; Heribert, K.; Franz, L.; et al. Austrian Guidelines for Outdoor Lighting; May 2019. Available online: https://www.land-oberoesterreich.gv.at/files/publikationen/us_ Leitfaden_Guidelines_Outdoor_lighting_english.pdf (accessed on 25 May 2021).

46. Grubisic, M.; Haim, A.; Bhusal, P.; Dominoni, D.M.; Gabriel, K.M.A.; Jechow, A.; Kupprat, F.; Lerner, A.; Marchant, P.; Riley, W.; et al. Light pollution, circadian photoreception, and melatonin in vertebrates. Sustainability 2019, 11, 6400. [CrossRef]

47. Bowmaker, J.K. Evolution of colour vision in vertebrates. Eye 1998, 12, 541. [CrossRef] [PubMed]

48. Hart, N.S. The visual ecology of avian photoreceptors. Prog. Retin. Eye Res. 2001, 20, 675-703. [CrossRef]

49. Kelber, A.; Vorobyev, M.; Osorio, D. Animal colour vision behavioural tests and physiological concepts. Biol. Rev. 2003, 78, 81-118. [CrossRef]

50. Aubé, M.; Roby, J.; Kocifaj, M. Evaluating potential spectral impacts of various artificial lights on melatonin suppression, photosynthesis, and star visibility. PLoS ONE 2013, 8, e67798. [CrossRef]

51. Falchi, F.; Cinzano, P.; Elvidge, C.D.; Keith, D.M.; Haim, A. Limiting the impact of light pollution on human health, environment and stellar visibility. J. Environ. Manag. 2011, 92, 2714-2722. [CrossRef]

52. Longcore, T.; Rodríguez, A.; Witherington, B.; Penniman, J.F.; Herf, L.; Herf, M. Rapid assessment of lamp spectrum to quantify ecological effects of light at night. J. Exp. Zool. Part A Ecol. Integr. Physiol. 2018, 329, 511-521. [CrossRef]

53. Licht und Natur. Standards of Low Impact Lighting (LIL). Available online: https://www.licht-und-natur.eu/lpec-in-eeb/ standards-of-low-impact-lighting/ (accessed on 25 May 2021).

54. Spoelstra, K. Spectrum dependent effects of artificial light at night. Biodiverse 2020, 3, 16.

55. Bertolotti, L.; Salmon, M. Do embedded roadway lights protect sea turtles? Environ. Manag. 2005, 36, 702-710. [CrossRef]

56. Robertson, K.; Booth, D.T.; Limpus, C.J. An assessment of 'turtle-friendly' lights on the sea-finding behaviour of loggerhead turtle hatchlings (Caretta caretta). Wildl. Res. 2016, 43, 27-37. [CrossRef]

57. IDA. The Bug System-A New Way to Control Stray Light from Outdoor Luminaires. A Classification System for Lighting Zones; Specifier Bulletin for Dark Sky Applications, 2009; Volume 2, pp. 1-6. Available online: http://shop.innovativelight.com/media/cms/ BUG_ratings_3044A7612FA89.pdf (accessed on 1 May 2021).

58. Davies, T.W.; Bennie, J.; Inger, R.; de Ibarra, N.H.; Gaston, K.J. Artificial light pollution: Are shifting spectral signatures changing the balance of species interactions? Global Chang. Biol. 2013, 19, 1417-1423. [CrossRef]

59. Lima, R.C.; Pinto da Cunha, J.; Peixinho, N. Light pollution: Assessment of sky glow on two dark sky regions of portugal. J. Toxicol. Environ. Health Part A Curr. Iss. 2016, 79, 307-319. [CrossRef] 
60. European Committee for Standardisation (CEN). Road Lighting_Part 2. Performance Requirements; EN 13201-2; CEN: Brussels, Belgium, 2016.

61. European Committee for Standardisation (CEN). Road Lighting_Part 5: Energy Performance Indicators; EN 13201-5; CEN: Brussels, Belgium, 2015.

62. Commission Internationale de l'Eclairage. Guide on the Limitation of the Effects of Obtrusive Light from Outdoor Lighting Installations; CIE 2017:150; CIE: Vienna, Austria, 2017.

63. Donatello, S.; Rodríguez Quintero, R.; Gama Caldas, M.; Wolf, O.; Van Tichelen, P.; Van Hoof, V.; Geerken, T. Revision of the Eu Green Public Procurement Criteria for Road Lighting and Traffic Signals; EUR 29631 EN; JRC115406; Publications Office of the European Union: Luxembourg, 2019. [CrossRef]

64. Puschnig, J.; Posch, T.; Uttenthaler, S. Night sky photometry and spectroscopy performed at the vienna university observatory. J. Quant. Spectrosc. Radiat. Transf. 2014, 139, 64-75. [CrossRef]

65. Azam, C.; Kerbiriou, C.; Vernet, A.; Julien, J.F.; Bas, Y.; Plichard, L.; Maratrat, J.; Le Viol, I. Is part-night lighting an effective measure to limit the impacts of artificial lighting on bats? Glob. Chang. Biol. 2015, 21, 4333-4341. [CrossRef] [PubMed]

66. Rowse, E.G.; Harris, S.; Jones, G. Effects of dimming light-emitting diode street lights on light-opportunistic and light-averse bats in suburban habitats. R. Soc. Open Sci. 2018, 5, 180205. [CrossRef]

67. Longcore, T.; Rich, C. Artificial Night Lighting and Protected Lands: Ecological Effects and Management Approaches; Natural Resource Report NPS/NRSS/NSNS/NRR—2016/1213; National Park Service: Fort Collins, CO, USA, 2016; pp. 1-51.

68. Boyce, P.R. The benefits of light at night. Build. Environ. 2019, 151, 356-367. [CrossRef]

69. Boyce, P.R.; Eklund, N.H.; Hamilton, B.J.; Bruno, L.D. Perceptions of safety at night in different lighting conditions. Lighting Res. Technol. 2000, 32, 79-88. [CrossRef]

70. IDA/IESNA. Model Lighting Ordinance (MLO) with Users Guide. Available online: http://www.darksky.org/wp-content/ uploads/bsk-pdf-manager/16_MLO_FINAL_JUNE2011.PDF (accessed on 31 January 2021).

71. Bortle, J.E.; Introducing the bortle dark-sky scale. Sky Telesc. 2001, 126-129. Available online: https://skyandtelescope.org/wpcontent/uploads/BortleDarkSkyScale.pdf (accessed on 1 February 2001).

72. Light Pollution Map. Available online: https:/ / www.lightpollutionmap.info (accessed on 21 March 2021).

73. Cinzano, P. The World Atlas of the Artificial Night Sky Brightness. Available online: http://www.lightpollution.it/worldatlas/ pages / fig1.htm (accessed on 21 March 2021).

74. Sanders, D.; Frago, E.; Kehoe, R.; Patterson, C.; Gaston, K.J. A meta-analysis of biological impacts of artificial light at night. Nat. Ecol. Evol. 2021, 5, 74-81. [CrossRef]

75. Cabrera-Cruz, S.A.; Smolinsky, J.A.; Buler, J.J. Light pollution is greatest within migration passage areas for nocturnally-migrating birds around the world. Sci. Rep. 2018, 8, 3261. [CrossRef]

76. Longcore, T.; Rich, C.; Mineau, P.; MacDonald, B.; Bert, D.G.; Sullivan, L.M.; Mutrie, E.; Gauthreaux, S.A.; Avery, M.L.; Crawford, R.L.; et al. Avian mortality at communication towers in the United States and Canada: Which species, how many, and where? Biol. Conserv. 2013, 158, 410-419. [CrossRef]

77. Gauthreaux, S.A.; Belser, C.G. Effects of artificial night lighting on migrating birds. In Ecological Consequences of Artificial Night Lighting; Rich, C., Longcore, T., Eds.; Island Press: Washington, DC, USA, 2006; pp. 67-93.

78. Squires, W.A.; Hanson, H.E. The destruction of birds at the lighthouses on the coast of California. Condor 1918, 20, 6-10. [CrossRef]

79. Evans-Ogden, L.J. Summary Report on the Bird Friendly Building Program: Effect of Light Reduction on Collision of Migratory Birds; 2002. Available online: http:/ / digitalcommons.unl.edu/flap/5/ (accessed on 25 May 2021).

80. Gehring, J.; Kerlinger, P.; Manville, A.M. Communication towers, lights, and birds: Successful methods of reducing the frequency of avian collisions. Ecol. Appl. 2009, 19, 505-514. [CrossRef]

81. Marquenie, J.; Donners, M.; Poot, H.; Steckel, W.; de Wit, B. Adapting the spectral composition of artificial lighting to safeguard the environment. In Proceedings of the 2008 5th Petroleum and Chemical Industry Conference Europe Electrical and Instrumentation Applications, 10-12 June 2008; pp. 1-6. Available online: https:/ / www.researchgate.net/publication/4350488_Adapting_the_ spectral_composition_of_artificial_lighting_to_safeguard_the_environment (accessed on 1 May 2021).

82. Falcón, J.; Torriglia, A.; Attia, D.; Viénot, F.; Gronfier, C.; Behar-Cohen, F.; Martinsons, C.; Hicks, D. Exposure to artificial light at night and the consequences for flora, fauna, and ecosystems. Front. Neurosci. 2020, 14, 1183. [CrossRef] [PubMed]

83. Canário, F.; Leitão, A.H.; Tomé, R. Predation attempts by short-eared and long-eared owls on migrating songbirds attracted to artificial lights. J. Raptor Res. 2012, 46, 232-234. [CrossRef]

84. Verheijen, F.J. The mechanisms of the trapping effect of artificial light sources upon animals. Arch. Néerlandaises Zool. 1960, 13, 1-107. [CrossRef]

85. Horváth, G.; Kriska, G.; Malik, P.; Robertson, B. Polarized light pollution: A new kind of ecological photopollution. Front. Ecol. Envir. 2009, 7, 317-325. [CrossRef]

86. Stone, E.L.; Harris, S.; Jones, G. Impacts of artificial lighting on bats: A review of challenges and solutions. Mamm. Biol. 2015, 80, 213-219. [CrossRef]

87. Barré, K.; Kerbiriou, C.; Ing, R.K.; Bas, Y.; Azam, C.; Le Viol, I.; Spoelstra, K. Bats seek refuge in cluttered environment when exposed to white and red lights at night. Mov. Ecol. 2021, 9, 3. [CrossRef]

88. Macgregor, C.J.; Evans, D.M.; Fox, R.; Pocock, M.J.O. The dark side of street lighting: Impacts on moths and evidence for the disruption of nocturnal pollen transport. Glob. Chang. Biol. 2017, 23, 697-707. [CrossRef] [PubMed] 
89. Bruce-White, C.; Shardlow, M. A Review of the Impact of Artificial Light on Invertebrates; Buglife-The Invertebrate Conservation Trust: 2011, pp 1-33. Available online: https:/ / cdn.buglife.org.uk/2019/08/A-Review-of-the-Impact-of-Artificial-Light-onInvertebrates-docx_0.pdf (accessed on 25 May 2021).

90. Rieswijk, C. Insects, Bats and Artificial Light at Night. Measures to Reduce Negative Effects of Light Pollution. Master Thesis, University of Utrecht, Utrecht, The Netherlands, 31 January 2014.

91. Stone, E.L. Bats and Lighting. Overview of Current Evidence and Mitigation; University of Bristol: Bristol, UK, 2013.

92. Avery, M.; Springer, P.F.; Cassel, J.F. Weather influences on nocturnal bird mortality at a north Dakota tower. Wilson Bull 1977, 89, 291-299.

93. Buchanan, B.W. Observed and potential effects of artificial night lighting on anuran amphibians. In Ecological Consequences of Artificial Night Lighting; Rich, C., Longcore, T., Eds.; Island Press: Washington, DC, USA, 2006; pp.192-220.

94. Spoelstra, K.; Visser, M.E. The impact of artificial light on avian ecology. In Avian Urban Ecology; Gil, D., Brumm, H., Eds.; Oxford University Press: Oxford, UK, 2013. [CrossRef]

95. Rotics, S.; Dayan, T.; Kronfeld-Schor, N. Effect of artificial night lighting on temporally partitioned spiny mice. J. Mammal. 2011, 92, 159-168. [CrossRef]

96. Davies, T.W.; Duffy, J.P.; Bennie, J.; Gaston, K.J. The nature, extent, and ecological implications of marine light pollution. Front. Ecol. Environ. 2014, 12, 347-355. [CrossRef]

97. Perry, G.; Buchanan, B.W.; Fisher, R.N.; Salmon, M.; Wise, S.E. Effects of artificial night lighting on amphibians and reptiles in urban environment. Herpetol. Conserv. 2008, 3, 239-256.

98. Brüning, A.; Hölker, F.; Franke, S.; Kleiner, W.; Kloas, W. Impact of different colours of artificial light at night on melatonin rhythm and gene expression of gonadotropins in european perch. Sci. Total Environ. 2016, 543, 214-222. [CrossRef]

99. Brüning, A.; Hölker, F.; Franke, S.; Preuer, T.; Kloas, W. Spotlight on fish: Light pollution affects circadian rhythms of european perch but does not cause stress. Sci. Total Environ. 2015, 511, 516-522. [CrossRef]

100. Moore, M.V.; Kohler, S.J.; Cheers, M.S. Artificial light at night in freshwater habitats and its potential ecological effects. In Ecological Consequences of Artificial Night Lighting; Rich, C., Longcore, T., Eds.; Island Press: Washington, DC, USA, 2006 ; pp. 365-384.

101. Marcantonio, M.; Pareeth, S.; Rocchini, D.; Metz, M.; Garzon-Lopez, C.X.; Neteler, M. The integration of artificial night-time lights in landscape ecology: A remote sensing approach. Ecol. Complex. 2015, 22, 109-120. [CrossRef]

102. Bennie, J.; Davies, T.W.; Inger, R.; Gaston, K.J. Mapping artificial lightscapes for ecological studies. Methods Ecol. Evol. 2014, 5, 534-540. [CrossRef]

103. Cinzano, P.; Falchi, F. Quantifying light pollution. J. Quant. Spectrosc. Radiat. Transf. 2014, 139, 13-20. [CrossRef]

104. Eisenbeis, G. Artificial night lighting and insects: Attraction of insects to streetlamps in a rural setting in Germany. In Ecological Consequences of Artificial Night Lighting; Rich, C., Longcore, T., Eds.; Island Press: Washington, DC, USA, 2006; pp. $281-304$.

105. Kuijper, D.P.J.; Schut, J.; van Dullemen, D.; Toorman, H.; Goossens, N.; Ouwehand, J.; Limpens, H.J.G.A. Experimental evidence of light disturbance along the commuting routes of pond bats (Myotis dasycneme). Lutra 2008, 51, 37-49.

106. Troy, J.R.; Holmes, N.D.; Green, M.C. Modeling artificial light viewed by fledgling seabirds. Ecosphere 2011, 2, art109. [CrossRef]

107. Hänel, A.; Posch, T.; Ribas, S.J.; Aubé, M.; Duriscoe, D.; Jechow, A.; Kollath, Z.; Lolkema, D.E.; Moore, C.; Schmidt, N.; et al. Measuring night sky brightness: Methods and challenges. J. Quant. Spectrosc. Radiat. Transf. 2018, 205, 278-290. [CrossRef]

108. Bouroussis, C.A.; Topalis, F.V. The effect of the spectral response of measurement instruments in the assessment of night sky brightness. J. Quant. Spectrosc. Radiat. Transf. 2018, 216, 56-69. [CrossRef]

109. Bouroussis, C.A.; Topalis, F.V. Assessment of outdoor lighting installations and their impact on light pollution using unmanned aircraft systems-The concept of the drone-gonio-photometer. J. Quant. Spectrosc. Radiat. Transf. 2020, 253, 107155. [CrossRef]

110. Jägerbrand, A.K. Development of an indicator system for local governments to plan and evaluate sustainable outdoor lighting. Sustainability 2021, 13, 1506. [CrossRef] 